\title{
Crianças Kaingang e as lógicas institucionais e étnicas de atendimento na cidade de Maringá, Brasil
}

\section{Assis da Costa Oliveira ${ }^{1}$ y Driéli Vieira ${ }^{2}$}

\author{
1 Universidade Federal do Pará, Altamira, Brasil \\ Orcid: 0000-0003-3207-7400 \\ Correo electrónico: assisdco@gmail.com \\ 2 Associação Indigenista de Maringá, Maringá, Brasil \\ Correo electrónico: drielivieira@gmail.com
}

Recibido:

15 de mayo de 2019 Aceptado:

11 de octubre de 2019

doi: 10.34096/runa.v40i2.6259

\section{Resumo}

No presente artigo objetivamos analisar o modo como se constituiu a relação entre indígenas e não-indígenas, mediados pelo "problema das crianças", para a construção de lógicas institucionais e étnicas de atendimento às situações relacionados ao trabalho, à educação, à convivência familiar e, sobretudo, às disputas pelos significados da infância e da pessoa Kaingang no contexto da cidade de Maringá, no estado do Paraná, Brasil. Trata-se de trabalho que utiliza o método de estudo de caso para problematizar determinadas cenas do histórico vivenciado pelo povo Kaingang, e particularmente pelas famílias da Terra Indígena Ivaí, na migração sazonal e estadia no espaço urbano para a venda do artesanato, o que gerou diferentes lógicas de produção de discursos e ações com base no agenciamento da identidade étnica e da cultura em articulação, ou não, com os direitos indígenas e a interculturalidade.

\section{Niños y niñas Kaingang y las lógicas institucionales y étnicas de intervención en la ciudad de Maringá, Brasil}

\section{Resumen}

En el presente artículo nos proponemos analizar el modo como se constituyó la relación entre indígenas y no indígenas, mediados por el "problema de los niños y niñas", para la construcción de lógicas institucionales y étnicas de atención a las situaciones relacionadas al trabajo, a la educación, a la convivencia familiar $y$, sobre todo, a las disputas por los significados de la infancia

\section{Palavras-chave}

Crianças indígenas; Povo Kaingang; Direitos das crianças e dos adolescentes; Direitos indígenas; Terra Indígena Ivaí
Palabras clave

Niños y niñas indígenas; Pueblo Kaingang; Derechos de niños, niñas y adolescentes; Derechos indígenas; Tierra indígena Ivaí 
y de la persona Kaingang en el contexto de la ciudad de Maringá, en el estado de Paraná, Brasil. Se trata de trabajo que utiliza el método de estudio de caso para problematizar determinadas escenas del histórico vivido por el pueblo Kaingang, y particularmente por las familias de la Tierra Indígena Ivaí, en la migración estacional y estancia en el espacio urbano para la venta de la artesanía, lo que generó diferentes lógicas de producción de discursos y acciones con base en el agenciamiento de la identidad étnica y de la cultura, en articulación, o no, con los derechos indígenas y la interculturalidad.

\section{Kaingang children and the institutional and ethnic logics of care in the city of Maringá, Brazil}

\section{Abstract}

Key words Indigenous children; Kaingang people; Rights of children and adolescents; Indigenous rights; Ivaí Indigenous Land

In the present article we aim to analyze the way in which the relationship between indigenous and non-indigenous people, mediated by the "problem of children", was constituted for the construction of institutional and ethnic logics of care to the situations related to work, education, family conviviality, and, mainly, to the disputes over the meanings of the Kaingang childhood and person in the context of the city of Maringá, in the state of Paraná, Brazil. It is a work that uses the case study method to problematize certain scenes of the history experienced by the Kaingang people, and particularly by the families of Ivaí Indigenous Land, in the seasonal migration and stay in the urban space for the sale of handicrafts, which generated different logics of production of discourses and actions based on the agency of ethnic identity and culture in articulation, or not, with indigenous rights and interculturality.

\section{Introdução}

Nos últimos anos, a experiência de mobilidade territorial do povo Kaingang para a produção e venda do artesanato, num deslocamento pendular entre as terras indígenas e os espaços urbanos, tem convivido e conflitado com diferentes agências estatais que procuram institucionalizar formas de simbolização e atendimento de suas crianças e famílias.

O fato de famílias Kaingang praticarem a produção e a venda do artesanato com a presença e o apoio de crianças é o foco central da disputa entre os serviços da rede de proteção e o povo Kaingang, em conjunto com as condições de deslocamento e estadia na cidade. Nisso, um conjunto de valores, categorias e normas é utilizado pelos agentes indígenas e não-indígenas para disputar diferentes concepções sobre infâncias, trabalho e convivência familiar, além das formas de tratamento institucional. Em tudo isso, existem regimes culturalmente localizados de imaginar a e agir na realidade e condições de vida das crianças Kaingang, as quais fazem operar modos variados de conceber o que seriam as vulnerabilidades e violências às suas vidas, assim como a proteção de seus direitos. 
Na cidade de Maringá, no estado do Paraná, Brasil, vem ocorrendo um destes enredos da presença, convivência e conflito de famílias Kaingang, sobretudo as provenientes da Terra Indígena Ivaí, com os serviços da rede de proteção local de crianças e adolescentes. Por isso, no presente artigo objetivamos analisar o modo como se constituiu a relação entre indígenas e não-indígenas, mediados pelo "problema das crianças", para a construção de lógicas institucionais e étnicas de atendimento às situações relacionados ao trabalho, à educação, à convivência familiar e, sobretudo, às disputas pelos significados da infância e da pessoa.

Trata-se de um trabalho que recorre ao método de estudo de caso para problematizar determinadas cenas (ou momentos) do histórico vivenciado no município, mas também uma análise da mobilidade do povo Kaingaing entre a terra indígena e a cidade. Utilizamos da observação participante e dos registros em áudio de situações marcantes acompanhadas por nós da migração Kaingang para a cidade de Maringá entre os anos de 2012 e 2019.

Na segunda sessão, o foco está na identificação das condições de vida do povo Kaingang na Terra Indígena Ivaí e os fatores socioeconômicos que influenciam a migração sazonal à cidade de Maringá, além da verificação sobre as percepções institucionais e sociais sobre a presença indígena no espaço urbano e de que maneira se mobiliza a cultura para justificar estereótipos e mecanismos de intervenção institucional. Na terceira parte, abordamos a discussão sobre as disputas de classificação do trabalho e da educação das crianças Kaingang nas interações entre indígenas e não-indígenas para definir os formatos de atendimento institucional e o que cabe à autonomia indígena.

A quarta sessão centra-se na compreensão da concepção Kaingang de cuidado e de partilha como conhecimentos e agencias centrais para a construção e a socialização da pessoa Kaingang, além de um contra-discurso para inversão do "problema das crianças" para uma avaliação dos modos não-indígenas de institucionalização do cuidado e da aprendizagem. Por último, na quinta parte, são apresentadas iniciativas mais recentes de reorganização das práticas estatais de planejar e intervir nas demandas indígenas, com base nos preceitos da interculturalidade e dos direitos indígenas.

\section{Ações e contradições do discurso protetivo: o caso das crianças Kaingang no Paraná}

O estado do Paraná, localizado na região Sul do território brasileiro, possui, atualmente, 27 terras indígenas, sendo apenas 17 demarcadas (PARELLADA, 2006), e a segunda maior delas (em população) é a Terra Indígena Ivaí (TI Ivaí), com 1.699 habitantes (IBGE, 2012), no município de Manoel Ribas, que possui uma população total de 13.169 pessoas - portanto, a população indígena representa $12,81 \%$. De acordo com Mota (2003), 70\% desta população é composta por crianças e jovens, o que demonstra a recuperação demográfica do grupo e o fortalecimento da identidade étnica, mas também um crescimento acelerado entre os anos de 2003 e 2010, período em que a população Kaingang aumento $59 \%$ na TI Ivaí. Conforme dados coletados na Unidade Básica de Saúde da Terra Indígena, em fevereiro de 2017, residiam 873 crianças e adolescentes entre 0 e 18 anos incompletos, representando $51,38 \%$ da população local, sendo 319 de zero a seis anos e 11 meses, 288 de sete a 11 anos e 11 meses, 266 de 12 a 17 anos e 11 meses. 
O processo de colonização da região do Sul do Brasil está historicamente relacionado ao incentivo da migração e ocupação da população europeia, principalmente após a abolição do regime escravocrata em 1888, e o extermínio e/ou expulsão dos povos indígenas dos seus territórios tradicionais. Para Nascimento (1978), a política de embranquecimento patrocinada pelo emergente Estado republicano brasileiro com o fomento da migração europeia tinha por objetivo o desaparecimento dos negros e dos indígenas, articuladas aos ideais de modernização e higienização da sociedade, o que tinha por premissa a supremacia da raça branca. Para os povos indígenas, a partir do século XX, também houve a instituição do poder tutelar como mecanismo de controle estatal e o consequente confinamento em reservas e terras indígenas com dimensões geográficas aquém da concepção étnica do território e em locais com solos e meio ambiente saturados por décadas ou séculos de exploração capitalista.

Isto também ocorreu à comunidade Kaingang que vive na TI Ivaí, a qual há muito tempo perdeu sua autonomia econômica - ante a impossibilidade de produção agrícola no território étnico que atenda as demandas da população atual - e passou a depender de políticas públicas para ter condições mínimas de sobrevivência. A única atividade em que esta população tem relativa autonomia é o artesanato confeccionado para venda, a principal fonte de renda das famílias. As oportunidades de trabalho dentro da terra indígena são escassas e menores ainda nas cidades em razão da falta de qualificação profissional. Segundo Mota (2003), apenas 1\% da população da TI Ivaí possui renda fixa como funcionários assalariados, $7 \%$ vivem de aposentadoria e $92 \%$ não possui renda fixa, estes dependem, necessariamente, das roças e da venda do artesanato.

Em razão do trabalho como artesãos da população Kaingang da TI Ivaí, sua presença nas cidades de todo estado do Paraná é constante e os conflitos culturais tornam-se (quase) inevitáveis. Para Tommasino (1998), esse movimento migratório (saída das terras indígenas para outras localidades) é uma prática comum entre os povos indígenas no Paraná, especialmente os Kaingang, pois estes costumavam fazer grandes expedições em busca de alimentos nos vastos territórios que hoje correspondem ao referido estado. Os povos Kaingang e Guarani continuam realizando esses movimentos migratórios, mas agora para as cidades, como Maringá, na intenção de obter os subsídios financeiros necessários, com a venda do artesanato aos fóg (não-indígenas), para a subsistência física e cultural.

No entanto, os momentos de contato entre os indígenas e os fóg também produzem o confronto de ideias, valores, hábitos e costumes. Nestas ocasiões, a identidade indígena é constantemente posta em questionamento pelos nãoindígenas, retroalimentada pelo imaginário social de que "lugar de índio é na floresta", e cuja inserção no meio urbano, e utilização de bens de consumo e serviços ali disponíveis, torna-se uma justificativa para a reprodução do discurso colonial que apregoa a "perda da cultura".

Na cidade de Maringá, esse tipo de comentário é muito comum e aponta para o racismo no modo de significação dos conceitos de identidade e cultura, valorando-os e hierarquizando-os com base no imaginário colonial do "índio ideal", em associação com uma moralidade institucional de culpabilização dos indígenas pelas suas situações socioeconômicas. Com isso, desloca-se a percepção das desigualdades sociais para o julgamento moral da cultura, produzindo um discurso de "culturalização da pobreza" e de essencialização de comportamentos (Szulc e Enriz, 2016), o qual tem por efeito a invisibilização das causas de estruturação de cenários de vida julgados como "problemas". 
Situação semelhante foi percebida e analisado por Mora (2017), no contexto de povos indígenas que recebiam serviços de desenvolvimento social - algo equiparado à serviços socioassistenciais - do governo de Tlapa, em Guerreiro, México, e cujos funcionários direcionavam a aplicação de um programa de geração de renda não para a superação das vulnerabilidades sociais, mas para "reeducar" os indígenas "para que entiendan a si mismos como sujetos activos y responsables de resolver su propio bien-estar" (2017, p. 285). Para a autora, a lógica de individualização dos problemas sociais, presente no âmago ideológico das políticas neoliberais, tem por efeito racial a desvalorização prévia das vidas das populações "beneficiadas", por serem responsabilizados pela incapacidade de romper com os ciclos intergeracionais de pobreza e desigualdade social, o que acirra ainda mais a legitimidade das políticas neoliberais socioassistenciais de intervirem nos indivíduos, mas não no social.

Assim, em vários momentos as características culturais da população Kaingang em Maringá são utilizadas pelo poder público para justificar as situações precárias de sobrevivência, como os acampamentos urbanos sem infraestrutura adequada à estadia digna na cidade, como se pode verificar mais abaixo (Imagem 1). Os serviços que lhes são oferecidos não atendem minimamente suas particularidades culturais, pois encontram-se dentro de "pacotes institucionais" já pré-estruturados e padronizados em nível nacional, o que implica na recusa por parte dos indígenas das "alternativas" que supostamente os tirariam da situação de vulnerabilidade a qual se encontram quando na estadia no meio urbano.

\section{Imagem 1. Acampamento Kaingang em Maringá}

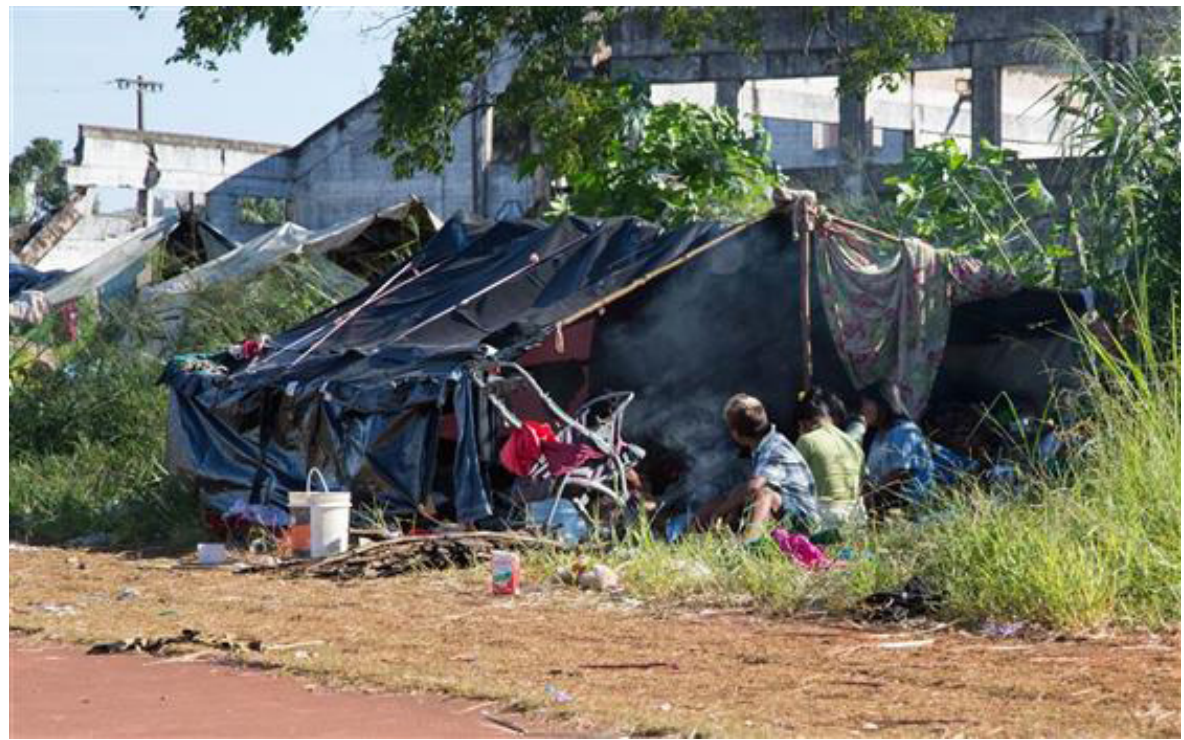

Fonte: Tadeu Santos.

Em 2016, a então secretária de Assistência Social de Maringá, Rosa Maria Marques, disse em entrevista a um jornal da cidade que "por causa da diferença entre as culturas, os índios não aceitam os serviços oferecidos pelo município, tais como convivência, atendimento pela rede socioassistencial e casa de passagem" (Filho, 2016). O discurso institucional passa a reputar aos indígenas a inadequação (cultural) aos serviços ofertados, de modo a isentar o Estado das responsabilidades para com o alinhamento dos mesmos serviços às especificidades étnico-culturais 
dos indígenas. E, assim, as diferenças culturais são transformadas, discursivamente, em hierarquizações raciais para justificar a não-assimilação indígena e os julgamentos morais sobre os modos de vida da alteridade.

Esse episódio também nos leva a reflexão sobre o mandamento jurídico do artigo 231 da Constituição Federal de 1988, o qual trata do reconhecimento e do respeito aos costumes, tradições, línguas, crenças, organização social e os direitos originários sobre as terras que ocupam os povos indígenas no Brasil, cabendo à União o dever de protegê-los e demarcar as terras indígenas. Porém, a permanência de serviços estatais, como no caso da política de assistência social, que não respeitam o direito à diferença dos povos indígenas demonstra a baixa influencia dos preceitos constitucionais no modus operandi dos serviços e profissionais.

Por certo, a temporalidade de resposta estatal às demandas estruturais por terra e sustentabilidade social, econômica e ambiental do povo Kaingang é diametralmente oposta àquela ofertada aos pretensos conflitos envolvendo suas crianças no espaço urbano. Conforme afirmam Szulc e Enriz (2016), na análise das disputas pelos direitos das crianças em cenários sociais envolvendo crianças Mapuche e Mbya Guarani na Argentina, quando se trata de ser demandado ante violações aos territórios indígenas a reação estatal é lenta e burocrática, quando não de omissão intencional ou de criminalização dos denunciantes, mas quando está em jogo a presença de crianças indígenas em espaços e atividades consideradas de "risco" nas cidades, a resposta do Estado é rápida e consistente: "esos niños deben ser retirados del allí y/o ser separados de sus familias y comunidades, consideradas ya sea incompetentes para cuidarlos o bien directamente culpables de descuidarlos" (2016, p. 208). A celeridade das medidas estatais na "proteção" às crianças, ao invés de solucionar ou mitigar as situações, tende a gerar mais conflitos e novas vulnerabilizações de direitos, além de desconsiderar as perspectivas indígenas sobre infância, família e trabalho (Szulc e Enriz, 2016).

Em relação ao acolhimento institucional, a política de assistência social fragmenta o atendimento aos sujeitos para concebê-los desde uma perspectiva individualizada, de modo a impedir o acolhimento da família em si, mas apenas de crianças e/ou mulheres em situação de extrema vulnerabilidade social. Porém, aos Kaingang é inconcebível separar os pais de seus filhos para que cada um seja acolhido em um abrigo. Além disso, esses estabelecimentos acolhem indivíduos que vivenciam rompimento de vínculos familiares, o que não acontece entre os grupos de artesãos que vêm até as cidades comercializar artesanato, os quais em nenhum momento tiveram "problema" com seus vínculos familiares e comunitários.

Viver desse modo na cidade, aos olhos da sociedade envolvente, é estar em permanente situação de vulnerabilização e até mesmo de violência, pois as condições de moradia são precárias, e a lógica estatal de justificar a precariedade acaba naturalizando a relação entre desigualdade social e diversidade cultural, reforçando, ainda mais, os imaginários estereotipados sobre o povo Kaingang.

No entanto, em muitos casos a vida dentro da terra indígena não é muito diferente da situação na qual essa população se encontra na cidade. Tal condição seria uma característica cultural ou fruto de desigualdade social vivenciada? Essas pessoas viverem em habitações precárias e sem saneamento básico, por exemplo, faria parte do seu modo de vida ou trata-se de uma consequência da falta de políticas públicas que atendam as suas demandas coletivas? Não caberia ao poder público proporcionar qualidade de vida àquelas famílias que 
se encontram nas cidades, tendo em vista que estar ali é uma necessidade para consecução da atividade que garante o sustento dos Kaingang?

Aqui, também se revela um outro aspecto da contradição do discurso da proteção: a intocabilidade dos sujeitos devido o risco da "perda cultural". Quando órgãos do poder público são cobrados por ações efetivas para atender a população indígena em Maringá, é comum ouvirmos que é preciso respeitar a cultura desses povos, numa concepção de respeito que anula qualquer possibilidade de ação estatal pelo simples fato de concebe-las como intervenções prejudiciais à manutenção do imaginário de preservação cultural dos sujeitos. Segundo Cariaga (2015), este é um mecanismo estatal de manejo da "identidade" e da "cultura" indígena como um outro intocável - ou cuja intervenção poderia provocar danos irremediáveis - a fim de produzir um efeito de impedimento, portanto, de omissão do Estado.

Em contrapartida, quando o poder público cobra providências da própria comunidade indígena, a situação que tanto incomoda a sociedade nacional deixa de ser explicitamente uma questão cultural e passa a ser tratada como uma questão de direitos - ou a violação deles, especialmente da "vulnerabilidade" das crianças indígenas - ainda que, no fundo, a "cultura" converta-se num recurso discursivo para culpabilização e responsabilização dos indígenas pelos direitos de suas crianças (Cariaga, 2015).

Assim, ocorre a criminalização das práticas Kaingang de cuidado e socialização das crianças ao investir no julgamento delas como situações de "risco", em que, em suma, coloca-se em risco o modelo de infância sustentado pelo Estado e pelos direitos (Szulc e Enriz, 2016), e não necessariamente àquele relacionado às condições sociais de vida e aos ideários Kaingang de bem-estar e proteção de direitos às crianças.

As restrições a participação social das crianças, na venda do artesanato ou na presença na rua, embasam-se numa concepção universal de infância moderna que historicamente apartou as crianças dos processos produtivos e da socialização em ambientes públicos, classificando ambos como perigosos ao desenvolvimento sadio dos sujeitos, mas que, com isso, produziu a valoração das crianças que destoam desse padrão moral-jurídico, e de seus grupos sociais de origem, como anomalias ou patologias sociais, cuja única resposta é a intervenção repressiva-assistencial do Estado aos problemas em si, e não às causas deles. Como aponta Szulc (2018), em relação à repercussão socioestatal ante a participação política das crianças Mapuche nas atividades políticas do seu povo, na Argentina, o importante é compreender as tensões geradas pela participação das crianças e como elas se tornam "objetos" instrumentalizados pela gestão estatal para a criminalização da cultura e das famílias, reatualizando a condição de menoridade e a essencialização da infância.

Assim, há a retroalimentação do que Cohn (2013) classifica de concepções de infância que embasam a lógica político-simbólica de operacionalização dos serviços de atendimento às crianças, tendo por finalidade a validação e a constituição de matizes de ideais de infância, dispostos dicotomicamente, que variam conforme o campo de atuação de cada serviço. O bom e o mau aluno, a criança normal e anormal para o campo da saúde, a pessoa vulnerável para assistência social e o adolescente infrator, para a Justiça, são categorias técnicojurídicas que escondem propostas específicas de conceber a infância, as quais as crianças e os grupo sociais reagem de alguma forma, seja incorporando-as, expandindo-as ou negando-as. 
1. O Centro POP, cujo nome completo é Centro de Referência Especializada para Pessoas em Situação de Rua, é tecnicamente descrito pela Secretaria Especial de Desenvolvimento Social do Ministério da Cidadania (SEDS/MS), do governo federal brasileiro, como uma unidade pública voltada para o atendimento especializado à população em situação de rua. Deve ofertar, obrigatoriamente, o Serviço Especializado para Pessoas em Situação de Rua, que realiza atendimentos individuais e coletivos, oficinas e atividades de convívio e socialização, além de ações que incentivem o protagonismo e a participação social das pessoas em situação de rua. O Centro POP deve representar espaço de referência para o convívio social e o desenvolvimento de relações de solidariedade, afetividade e respeito (Brasil, 2015a).
No caso em análise, o saber socioassistencial de classificação da vulnerabilidade social num duplo viés: ora para evitar a "perda" de uma infância e cultura indígena idealizadas ante as formas de intervenção estatal; ora para revitalizar a predominância da infância não-vulnerável como um recurso para a discriminação às famílias Kaingang e a legitimação das ações de "proteção" de direitos. No entanto, em ambos também está presente a dificuldade pelo reconhecimento de outras infâncias, e da possibilidade de fazer desse posicionamento uma chave de leitura para a reconstrução dos direitos das crianças.

\section{Infância Kaingang e as concepções sobre educação e pes- soa: perspectivas para repensar os legados morais dos discur- sos protetivos}

É comum encontrarmos no discurso daqueles que "fazem a proteção" das crianças indígenas um tom etnocêntrico na percepção e valoração dos modos de cuidado e de representação dos "outros". Em uma ocasião, ocorrida em Maringá no ano de 2015, aconteceu uma capacitação para os servidores da Secretaria Municipal de Assistência Social, na qual também participavam lideranças indígenas, além de pesquisadores, indigenistas e apoiadores da causa indígena. Neste evento, uma servidora que trabalhava no Centro Pop1 relatou sua preocupação com as crianças indígenas na cidade e que o trabalho de sua equipe era "protege-las de possíveis situações de risco". Um dos indígenas presentes se manifestou prontamente afirmando que ela poderia ficar tranquila, pois eles (Kaingang) "sabiam cuidar de seus filhos". Para o pai, o fato do filho estar junto dele, inclusive no momento da comercialização do artesanato, lhe assegura proteção e faz parte do seu processo de aprendizagem e socialização como pessoa Kaingang.

Acima de cinco anos já participa desse nosso trabalho porque os índios nasceu junto com esse artesão. Se o meu piazinho crescer mais, vai fazer artesão que eu tô fazendo com a mãe dele. Nós mesmo que ensina as nossas crianças. O meu piazinho, se eu fizer alguma coisa ele vai tá por perto pra fazer isso também. Outro dia eu tava limpando aqui, aí o piazinho foi lá e catou os lixos comigo. Isso que eu tô dando bom exemplo pra ele fazer depois, né! (Liderança Kaingang, gravação de 03/03/2015).

Numa outra ocasião, em razão da intervenção do Ministério Público, uma organização da sociedade civil, a Associação Indigenista (ASSINDI) Maringá, que acolhe a população Kaingang no município com o objetivo de humanizar a sua estadia na cidade, foi convidada a prestar informações à Promotoria da Infância e Juventude do Ministério Público do Estado do Paraná (MPE/PR) sobre a presença das crianças indígenas nas ruas, vendendo cestos e pedindo dinheiro nos sinaleiros das grandes avenidas da cidade.

Em virtude deste convite, a equipe técnica da organização se reuniu com as famílias Kaingang para saber o que elas próprias teriam a dizer da situação e suas contribuições foram de grande importância para o desfecho deste conflito, tanto que dois representantes Kaingang escolhidos naquela ocasião foram até o MPE/PR para expor os seus pontos de vista a respeito das demandas levantadas pelo promotor. Nesta ocasião, os sujeitos, que também eram pais, reforçaram a importância da presença das crianças Kaingang nas cidades para que pudessem aprender um ofício e garantir o sustento da família que um dia viriam a constituir. Além disso, naquele ambiente a criança aprende a se "comportar na cidade", ou seja, a obter um conjunto de habilidades e expertises do fóg que as tornem mais aptas de viverem na sociedade não-indígena, 
como: falar a língua portuguesa; negociar com maior igualdade de condições junto ao fóg, e a partir da aprendizagem de suas habilidades de negociação; e, conseguir comida e demais itens necessários ao seu sustento e de sua família.

Para as famílias indígenas alojadas na ASSINDI, a produção e venda do artesanato faz parte do processo educativo das crianças Kaingang, uma educação que não se aprende na escola, mas sim que é de responsabilidade da família. Isto se relaciona com o que Oliveira (2014 e 2016) aponta sobre o processo da educação tradicional entre os povos indígenas ter uma relação direta com a prática e a experimentação, portanto, com a ideia do "aprender fazendo". As crianças inseridas nas tarefas domésticas e produtivas das famílias para obterem as habilidades e os conhecimentos necessários à suas subsistências físicas, ao apoio nos afazeres familiares, mas, sobretudo, à construção, à socialização e ao reconhecimento sociocultural como pessoa indígena.

A "liberdade de praticar" da criança Kaingang a venda do artesanato nas ruas de Maringá, vista como uma negligência familiar pelos não-indígenas, era, aos olhos dos Kaingang, uma forma de zelar pelos seus futuros, atentos à necessidade de aprender no presente os conhecimentos e as habilidades da fabricação e da venda do artesanato (Oliveira, 2016).

Porém, em razão da reunião com o Ministério Público, os indígenas presentes foram questionados pela equipe quanto a presença de seus filhos na escola, afinal, quando estão nas cidades as crianças estão fora da instituição escolar. Os indígenas, no discurso, reconheceram a importância da escola, mas enfatizaram muito mais o conhecimento a ser adquirido fora dela para a formação da pessoa Kaingang, no sentido de aprender e ser reconhecido como um artesão, pois fazer artesanato é uma tradição passada de geração em geração e essa arte é o patrimônio que os pais têm a deixar aos seus filhos.

Segundo Tassinari (2007), a concepção indígena sobre infância e desenvolvimento infantil perpassa o reconhecimento da criança como sujeito de sua aprendizagem - o que não retira dos adultos indígenas a responsabilidade por sua educação - e socialização, na medida em que participam da vida social. Por isso, a ideia de resguardá-las em "espaços infantis", sobretudo nas escolas e creches, retirando-as das dinâmicas de convivência social, "é também uma forma de retirar das crianças sua autonomia frente à própria educação" (2007, p. 16). Trata-se de um mecanismos estatal de desconsideração (ou deslegitimação) das noções de infâncias compartilhadas pelos Kaingang, assim como pelos Mapuche e os Mbya Guarani, entre outros povos indígenas, segundo a qual as crianças são constituídas como "sujetos activos de sus comunidades, teniendo plena participación en las distintas actividades e iniciativas de su grupo (...), incluyendo por lo tanto las atividades productivas y reivindicativas" (Szulc e Enriz, 2016, p. 209).

Além disso, o fato da criança Kaingang estar em formação para ser um artesão relaciona-se à concepção indígena de ensinamento de valores morais, éticos e técnicos para a produção de corpos saudáveis (Tassinari, 2007). Nisso, o uso da oratória torna-se secundário frente o referencial educacional do "aprender fazendo", e a noção de bem-estar e saúde da criança tornam-se dependentes da sua fabricação como pessoa artesã.

A partir dos relatos dos adultos Kaingang foi possível perceber outras noções de tempo e de espaço da aprendizagem. Esse aprendizado que possivelmente implicará na futura profissão das crianças parece acontecer desde muito cedo, 
pois estão envolvidas nesses processos produtivos. No entanto, é "cedo" para nós não-indígenas (fóg), pois é preciso considerar que esses meninos e meninas são considerados adultos a partir dos 13 ou 14 anos, média de idade em que acontecem os casamentos e nesta fase eles assumem responsabilidades de uma pessoa adulta, como os cuidados da casa e o sustento da família. Conforme Faustino (2010), é justamente nessa faixa etária em que aparecem os maiores índices de evasão escolar, o que nos faz acreditar que a vida conjugal e comunitária não é compatível com a escolar, ou melhor, que a escola não está preparada para lidar com estas dinâmicas de parentesco e trabalho que envolvem o tornar-se uma pessoa Kaingang.

\section{A concepção de cuidado Kaingang e os (des)encontros ins- titucionais}

No ano de 2012, os dirigentes da ASSINDI, percebendo a presença das crianças Kaingang na cidade de Maringá e o incômodo da sociedade envolvente frente à realidade, criou um centro social indígena, cujo objetivo era proporcionar aos pais a opção de deixar seus filhos na organização enquanto saíam para trabalhar. Após alguns meses de início do projeto, percebeu-se que a iniciativa não havia tido adesão pelas famílias, o que causou espanto na equipe da organização. Afinal, na época falava-se tanto da necessidade de abertura de creches para atender filhos de trabalhadores não-indígenas e as famílias Kaingang tinham naquela organização um espaço de atendimento educacional às suas crianças em tempo integral e com profissionais qualificados, materiais pedagógicos, brinquedos e jogos disponíveis, além de um refeitório no qual eram servidas três refeições diárias. Mas a frequência das crianças Kaingang era de participação em poucas horas e apenas no período da manhã, pois após o almoço elas acompanhavam seus pais até o centro da cidade para a venda do artesanato.

Quando as famílias foram questionadas sobre a baixa participação na iniciativa, a resposta veio rápida e certeira: "quem deixa o filho pra outro cuidar é branco, Kaingang não faz isso!" A partir deste ponto de vista é possível perceber uma outra noção de cuidado, pois para aqueles indígenas o cuidado com as crianças é de responsabilidade da família, e não da instituição administrada pelo fóg. Não fazia sentido uma criança passar tanto tempo longe dos pais, pois a aprendizagem da (e do tornar-se a) pessoa Kaingang se faz no contato, na relação e na prática, nunca na separação do sujeito-criança de seu grupo de pertença cultural, que é como acontece com as crianças não-indígenas que entram nas escola às oito horas da manhã e, muitas vezes, saem somente às dezoito horas. Uma das mães presentes disse acreditar que essa distância entre a criança não-indígena e sua família era a responsável pelo comportamento inadequado de "nossos filhos" que ela acompanhava pela televisão, afinal "quem cria os filhos do branco é a escola e não a família". Ela considerava como comportamento inadequado, por exemplo, roubar, por isso ensinava seus filhos a pedir: "pedir é bom, roubar é ruim!"

A noção do pedir desde a ótica indígena é a de gerar um vínculo de reciprocidade e de consentimento com o outro não-indígena para apoio à sua demanda de subsistência. É, no fundo, uma ação sustentada por um preceito ético de solidariedade e não-violência, em que o fóg assente em contribuir financeiramente, ao mesmo tempo em que o Kaingang transmite sua satisfação. Tal conhecimento só é possível de apreensão, na concepção Kaingang, quando a criança "aprende fazendo" com os membros de sua família, evitando, assim, 
o aprendizado e a reprodução de comportamentos inadequados, sobretudo os violentos ou de desrespeito intergeracional.

É interessante também perceber a inversão do julgamento moral que ocorre na fala da mulher Kaingang. Agora, a própria institucionalização do cuidado e do aprendizado das crianças não-indígenas se desnaturaliza, de modo a apontar as consequências negativas desde uma perspectiva Kaingang, centralizada na transferência da responsabilidade da família para a escola. Mas, com isso, coloca em questionamento os fundamentos coloniais/modernos da família e da escola, e até que ponto (não) estão servindo para a produção da educação de qualidade das crianças.

Quanto ao pedir dinheiro (ou trocadinho), a equipe da organização buscou apresentar aos Kaingang a perspectiva não-indígena de valoração desta conduta, isto é, a mendicância e a feição pejorativa que carrega consigo na sociedade não-indígena. No meio da explicação um homem, pai de três filhos, exclamou "eu não sei qual é o problema do branco em dividir o que tem", pois, segundo ele, na aldeia é assim que se faz, é partilha, quem tem um pouco mais ajuda quem tem menos.

A partilha sintetiza o valor da solidariedade e do viver em coletividade. Há nisso todo um investimento simbólico e educativo nos valores morais e éticos do "ser Kaingang" para a construção de corpos saudáveis (Tassinari, 2007), inclusive no que este bem-estar representa em termos coletivos e comunitários. Portanto, a partilha de recursos econômicos, seja na terra indígena ou na cidade, é concebido como um comportamento calcado na solidariedade e na reciprocidade, valores que aos olhos dos Kaingang devem ser incorporados pelas crianças Kaingang e também pelos não-indígenas.

Toda essa percepção Kaingang acerca do processo educativo de suas crianças foi relatada ao promotor da Promotoria da Infância e da Juventude do MPE/PR que compreendeu a situação sob a perspectiva indígena, conheceu parte da realidade vivenciada por aquelas famílias e apenas ratificou a necessidade de que elas tomassem cuidado com seus filhos pelas ruas da cidade, alertando-os dos perigos de transitar nos movimentados cruzamentos das principais avenidas.

Este promotor teve uma sensibilidade que poucos têm, se dispôs a ouvir o que o artesão - aquele que vai para rua e busca o sustento da família na venda do artesanato - tinha a dizer, e distanciar-se dos seus referenciais culturais nãoindígenas para melhor compreender os sentidos étnicos e, com isso, o modo de interpretar a legislação relativa aos direitos das crianças e dos adolescentes. Sem dúvida, é preciso multiplicar a qualificação dos profissionais para que, de fato, se preocupem com os povos indígenas conhecendo suas realidades e contemplando as suas demandas, sobretudo as coletivas.

\section{A ASSINDI e a proposta de reeducação intercultural à so- ciedade de Maringá}

No início dos anos 2000 a cidade de Maringá passou a ser procurada pela população Kaingang para comercialização do artesanato. Nesse mesmo período o estado do Paraná criava uma política afirmativa de inclusão dos povos indígenas nas universidades públicas o que, segundo a historiadora da Universidade Estadual de Maringá, Isabel Rodrigues, no documentário "Veredas Kaingang"2, produzido pela ASSINDI em 2017, diz ter popularizado
2. Documentário disponível em: <https://www.youtube.com/ watch? $v=$ bsyAKhds Jjk $>$. 
o município entre a população indígena da região, pois várias instituições universitárias locais passaram a oportunizar o acesso aos estudantes indígenas, impulsionando um (novo) fluxo de migração sazonal.

Foi dentro desse contexto que a ASSINDI foi oficialmente fundada, no ano de 2001. A atual presidente e fundadora da organização se deparou com a realidade das famílias Kaingang em Maringá e percebeu a necessidade de humanizar a estadia daquelas pessoas na cidade, oferecendo-lhes um serviço de acolhimento, assessoramento, defesa e garantia de direitos, como a da primeira família atendida, cujo registro visual segue abaixo (Imagem 2). Isto, por certo, ante a constatação da omissão do poder público em prestar tais serviços e do aumento do racismo da sociedade maringaense.

\section{Imagem 2. Primeira família acolhida pela ASSINDI}

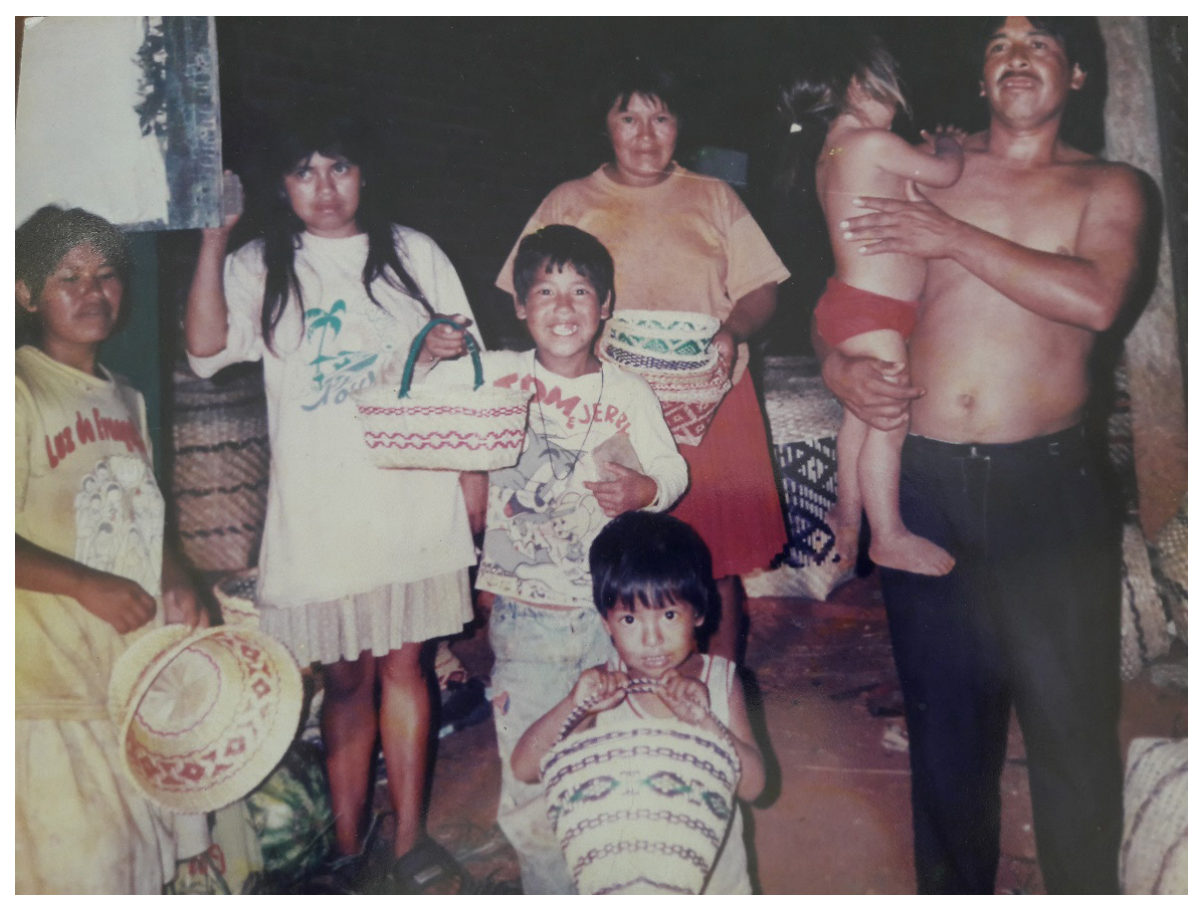

Fonte: acervo da ASSINDI.

Desde então, esta organização vem promovendo discussões com a sociedade local e os povos indígenas visando a valorização e o respeito à diversidade cultural, especialmente com a promoção de formas de educação e comunicação social que reorientem a população não-indígena para a melhor compreensão dos povos indígenas e de seus direitos coletivos, relativizando as lógicas culturais não-indígenas e apropriando-se dos elementos que estruturam o direito à diferença.

Por isso, de 2014 a 2015 a ASSINDI realizou um ciclo de debates no qual foram convidados especialistas em diferentes temas relativos aos povos indígenas a fim de apresentar outras experiências de tratamento institucional em diferentes municípios e com outros grupos étnicos, além de buscar subsídios teóricos, metodológicos e normativos que qualificassem a atuação das instituições locais e a reeducação intercultural da sociedade. 
O primeiro encontro, em abril de 2014, tratou da presença indígena na cidade pautada na experiência da Prefeitura de Porto Alegre, no Rio Grande do Sul, e a criação da política pública chamada "Mulheres dos Panos" a qual reconhece, no âmbito municipal, "as práticas do poraró3 e as apresentações dos grupos musicais Mbyá Guarani realizadas em espaços públicos como expressões legítimas da cultura indígena, conforme seus usos, costumes, organização social, línguas, religiosidade e tradições" (Prefeitura de Porto Alegre, 2011).

O segundo, realizado em maio de 2014, abordou questões afetas ao assessoramento, defesa e garantia de direitos dessa população no estado do Paraná e a atuação do Centro de Apoio Operacional das Promotorias de Justiça de Proteção às Comunidades Indígenas (CAOP). E, por fim, no terceiro diálogo, em junho de 2015, foi debatida a presença das crianças indígenas no município de Maringá sob a perspectiva da Doutrina de Proteção Plural das crianças indígenas (Oliveira, 2014).

Este processo formativo da sociedade maringaense logrou a visibilidade da realidade e, consequentemente, das demandas dos povos indígenas. Com o tempo, novas conquistas foram alcançadas como a aproximação do poder público, por meio da implementação de políticas setoriais (saúde, assistência social e geração de renda) com a população indígena.

Desde então, a temática indígena tem estado em pauta no município. A saber, em 2014 a 3ํㅗ Promotoria de Justiça de Maringá realizou uma mesa redonda para tratar da abordagem às famílias indígenas visando a proteção das crianças. Em 2016 foi organizada uma comitiva composta por esferas do poder público, como: Secretaria de Assistência Social; Secretaria Municipal de Cultura; MPE/ PR; Fundação Nacional do Índio (Funai); e, o terceiro setor, representado pela ASSINDI. O foco foi a ida ao município de Manoel Ribas, cidade onde se localiza a TI Ivaí, visando conhecer a realidade das famílias Kaingang que vão até Maringá comercializar artesanato e, a partir disto, produzir encaminhamentos acerca da elaboração de mecanismos institucionais para a redução da situação de vulnerabilidade daquelas famílias.

Nesta ocasião, foi criado um grupo de trabalho composto por autoridades de Maringá, Manoel Ribas, Funai e lideranças indígenas, com vistas a alcançar os objetivos previstos no primeiro encontro, que seriam: a criação de espaços para a venda de artesanatos indígenas; e, uma casa de passagem 4 no município de Maringá para melhor atender essa população. Além disso, está o comprometimento do apoio da Prefeitura de Manoel Ribas e da Funai para superação da situação de vulnerabilidade das famílias Kaingang da TI Ivaí, por meio de projetos de geração de renda voltados à produção agrícola e comercialização do artesanato.

A proposta metodológica desse e dos demais encontros foi a da escuta intercultural, isto é, ouvir o que as autoridades e a população em geral têm a dizer sobre os povos indígenas e ouvir também o que os povos indígenas tem a falar sobre si e sobre os outros (no caso, nós, os não-indígenas), de modo a tirar desta discussão um planejamento decisório que intervisse nas causas da vulnerabilidade, e não em suas consequências ou na centralização como "problema das crianças". A partir daí foi possível pensar em políticas e serviços com os povos indígenas e respeitando a interculturalidade no planejamento e na implementação.
3. Entende-se por poraró a presença de mulheres Mbya-Guarani sentadas em panos no chão, nos espaços públicos, acompanhadas ou não de suas crianças, onde comercializam bens de seu patrimônio material e imaterial e recebem doações de não-indígenas.

4. Segundo a SEDS/MS, as casas de passagem são serviços de acolhimento provisório destinadas a receber no máximo de 50 (cinquenta) pessoas, caracteriza-se pela oferta de acolhimento imediato e emergencial, distingue-se por ter um fluxo mais rápido, uma vez que recebe indivíduos em trânsito, com uma permanência máxima de 90 dias" (Brasil, 2015b). 
5. Lei Municipal n. 10.061 foi aprovada em 2015, mas entrou em vigor apenas em 2018.

6. Lei Municipal no 10.844/2019.
O resultado disso foi a aprovação da lei que garante vale transporte aos indígenas que vêm à Maringá vender artesanato5. Também, o município, em 2017, criou a "Casa do Índio", serviço de acolhimento como forma de complementar o trabalho da ASSINDI, atendendo àqueles que não podem ser acolhidos lá. Em 2019, os vereadores de Maringá aprovam, por unanimidade, uma lei6 que cria o Encontro de Culturas Indígenas que acontecerá todos os anos no município, procurando ofertar um espaço de promoção das tradições, línguas e artes indígenas, de modo a mostrar à população local uma faceta indígena mais ligada as suas potencialidades, e não as vulnerabilidades, o que contribui para a reversão de discriminações.

O MPE/PR e o Procuradoria Regional do Trabalho da 9a Região também acompanham a pauta indígena, especialmente a questão da presença das crianças Kaingang na cidade e a participação das mesmas na comercialização do artesanato, e têm sido um dos maiores apoiadores dos projetos voltados à população indígena em Maringá.

Desta forma, acredita-se que com a aproximação entre a população indígena e a sociedade nacional, respaldada por um diálogo pautado na interculturalidade e nos direitos indígenas, está-se a construir um outro caminho às relações interétnicas no município de Maringá, ainda que se deva sempre estar atento às novas formas de reprodução de discriminações e violências, mesmo quando embasadas em discursos de vanguarda dos direitos e do tratamento institucional.

Em suma, é preciso atentar para o reconhecimento do momento de transição da relação entre povos indígenas e Estado no contexto do município, mas que pode sofrer retrocessos e revisões, ainda mais quando, em nível nacional, tem-se o avanço de discursos de ódio e de redução do custeio da máquina estatal às políticas públicas, sobretudo às de caráter social, no atual governo de Jair Bolsonaro e de vários governadores que seguem a mesma linha políticoideológica de avanço do neoliberalismo e de recrudescimento do papel e dos compromissos jurídico-políticos do Estado de Direito.

\section{Considerações finais}

\author{
O índio é forte e sobrevive jogado à própria sorte \\ Como pode, sem terra pra morar, sem rio para pescar \\ O Juruá desmata a mata e mata os M'bya \\ Mas Wera MC e Oz Guarani não cansa de lutar, e seguiremos assim até a morte \\ $O$ índio é forte
}

(Oz Guarani)

Inspirados nas palavras do grupo de rap indígena Oz Guarani, com um trecho da música "Índio é forte"7, discutimos ao longo deste artigo as relações entre o juruá ou fog (não-indígena) com os Kaingang no contexto da cidade de Maringá, e tendo por enredo a migração sazonal e a presença indígena no espaço urbano, com centralidade nas classificações raciais e formas de agenciamento dos direitos de crianças e adolescentes para tratar de assuntos ligados ao trabalho, educação, convivência familiar e concepções de infância.

Apesar da conjuntura eminentemente contemporânea dos conflitos sócioinstitucionais analisados, os motivos da migração Kaingang da TI Ivaí para 
Maringá foram historicamente estabelecidos, relacionados à política indigenista de demarcação das reservas e terras indígenas no Sul do Brasil e ao processo de espoliação do meio ambiente e do território, o que ocasionou a inviabilização da garantia de condições de subsistência física, econômica e cultural, associado ao crescimento demográfico da população Kaingang. Com isso, a produção e a venda do artesanato se constituíram em estratégias fundamentais para a obtenção de recursos financeiros necessários à manutenção das famílias e da comunidade.

Porém, o deslocamento e a estadia na cidade de Maringá, assim como a venda do artesanato nas ruas com a presença das crianças, intensificou os julgamentos discriminatórios da sociedade e das instituições da rede de proteção local, com uso de dois recursos discursivos: por um lado, alegando que as diferenças culturais são os motivos para a marginalização social e a incompatibilidade dos sujeitos com as políticas ofertadas para atende-los, sobretudo as de assistência social; por outro, uma perspectiva de intocabilidade do indígena, em que qualquer forma de intervenção geraria uma correlata "perda cultura", por isso inviabilizando o atendimento institucional. Em ambos os casos, a identidade étnica e a cultura são categorias utilizadas para construir uma naturalização das desigualdades sociais e a reprodução de hierarquias raciais, portanto, de um racismo institucional.

Em todos esses jogos discursivos sócio-institucionais, e as ações interventivas propostas, os Kaingang colocam-se num contra-discurso de afirmação e valorização dos modos culturalmente embasados de cuidado, trabalho, educação e construção e socialização da pessoa Kaingang. As contraposições discursivas dos Kaingang revelam um processo mais complexo de compreensão da presença das crianças nos diferentes atos da vida em sociedade, demonstrando que, a todo momento, elas estão "aprendendo fazendo" e, assim, constituindose como pessoa para si e para os membros do grupo. Além disso, ao analisarem o processo de institucionalização do cuidado das crianças dos fóg, a crítica Kaingang sobre as consequências negativas disto para o comportamento das crianças não-indígenas é também uma forma de desnaturalizar os fundamentos coloniais/modernos da família e da escola.

Com o passar do tempo e, sobretudo, com a maior escuta e participação dos membros Kaingang, a rede de proteção passou a rever seus preceitos legais e institucionais, buscando: compreender a realidade social, cultural e econômica da população Kaingang desde às condições de vida na TI Ivaí para ampliar o horizonte de percepção sobre as causas da vulnerabilidade socioeconômica e da migração sazonal, com o correlato comprometimento de outros agentes estatais, como a Prefeitura de Manoel Ribas e a Funai, para a implantação de projetos de geração de renda na terra indígena; a estruturação de recursos normativo-institucionais (vale transporte indígena, espaço social para venda do artesanato, Casa do Índio e Encontro das Culturas Indígenas) que atenda as demandas indígenas para deslocamento e estadia na cidade de Maringá, além de estimular os intercâmbios interculturais e a visualização dos aspectos positivos do povo Kaingang, mais além do artesanato.

Por certo, estas são medidas que precisam ser monitoradas e avaliadas nos próximos anos para saber de que forma geraram resultados positivos e, também, quais as novas reproduções da discriminação contra o povo Kaingang, mesmo sob uma base de respeito às identidades e aos direitos indígenas. 
Infelizmente, os tempos atuais não são propícios, no Brasil, à expansão das garantias dos direitos indígenas, muito pelo contrário. Desde a chegada de Jair Bolsonaro à Presidência da República, o discurso de ódio às diversidades sociais e a prática de desmantelamento acelerado dos direitos fundamentais do povo brasileiro, incluindo os direitos específicos aos povos indígenas, tem colocado o desafio de promover uma resistência social cotidiana frente à barbárie da extrema direita no poder central do país.

Porém, para o povo Kaingang, no município de Maringá, uma chama de esperança intercultural foi acesa nos últimos anos, com apoio de diferentes instituições dos poderes Executivo, Legislativo e Judiciário. Isto pode tornar-se uma referência para outros contextos de presença indígena nas cidades, especialmente na região Sul do país, mas sempre com o cuidado de não buscar copiar os modelos, apenas intentando apropriar-se das metodologias e dos formatos de atividades realizados, e tranversalizando isto com os direitos indígenas, a interculturalidade e, fundamentalmente, o protagonismo indígena.

\section{Sobre los/as autores/as}

Assis da Costa Oliveira é professor de Direitos Humanos da Faculdade de Etnodiversidade da Universidade Federal do Pará (UFPA), Campus de Altamira. Doutorando pelo Programa de Pós-Graduação em Direito da Universidade de Brasília. Doutorado sanduíche no Programa de Pós-Graduação em Antropologia da Escola Nacional de Antropologia e História, no México, com apoio da CAPES. Mestre pelo Programa de Pós-Graduação em Direito da UFPA. Graduado em Direito pela UFPA. Coordenador do Grupo Temático Direitos, Infâncias e Juventudes do Instituto de Pesquisa Direitos e Movimentos Sociais. Membro da Associação Brasileira de Antropologia e Advogado.

Driéli Vieira é mestre em Ciências Sociais pela Universidade Estadual de Maringá. Membro da equipe técnica da Associação Indigenista (ASSINDI) - Maringá. Coordenadora do Serviço de Acolhimento Emergencial e Transitório - Casa de Passagem Indígena conduzido pela ASSINDI. 


\section{Q Referencias bibliográficas}

"Brasil (2015a). Centro de Referência Especializado para Pessoas em Situação de Rua - Centro POP. Brasília: SEDS/MC. Disponível em: http://mds.gov.br/assuntos/assistenciasocial/unidades-de-atendimento/centro-pop

"Brasil (2015b). Serviço de Acolhimento para Adultos e Famílias. Brasília: SEDS/MC. Disponível em: http://mds.gov.br/assuntos/assistencia-social/unidades-de-atendimento/ unidades-de-acolhimento/servico-de-acolhimento-para-adultos-e-familias

»Cariaga, D. E. (2015). "E quando a 'cultura' vira um problema?”: relações entre a educação das crianças Kaiowa e Guarani e a rede de garantia de direitos em Te'Ýikue, Caarapó - MS. Espaço Ameríndio, 9 (3), 226-256. doi: 10.22456/1982-6524.58373

» Cohn, C. (2013). Concepções de infância e infâncias: um estado da arte da antropologia da criança no Brasil. Em: Civitas, 13 (2), 221-244, maio-ago.

" Faustino, R. C. (2010). Aprendizagem escolar entre indígenas Kaingang no Paraná: questões sobre língua, alfabetização e letramento. Práxis Educativa, Ponta Grossa, v.5, n.2, p. 213-219, jul.-dez. Disponível em http://www.periodicos.uepg.br

"Filho, A. (2016). Índios migram para vender ou estudar. Jornal Matéria Prima. Disponível em: http://www.jornalmateriaprima.com.br/2016/o5/indios-migram-para-vender-ouestudar/

» IBGE (2012). Os indígenas no Censo Demográfico 2010: primeiras considerações no quesito cor ou raça. Rio de Janeiro: IBGE/MPOG. Disponível em: https://indigenas.ibge.gov.br/ images/indigenas/estudos/indigena_censo2010.pdf

" Mora, M. (2017). Racismo y criminalización en México. Reflexiones críticas desde la Montaña de Guerrero. Em: S. Bastos e M. T. Sierra (coords.). Pueblos indígenas e Estado em México: la disputa por la justicia y los derechos (pp. 270-295). Mexico: Centro de Investigaciones y Estudios Superiores em Antropología Social.

» Mota, Lucio T. (2003). Diagnóstico etno-ambiental da Terra Indígena Ivaí - PR. Maringá: Programa Interdisciplinar de Estudos de Populações; Laboratório de Arqueologia, Etnologia e Etno-História/UEM.

» Nascimento, A. (1978). O genocídio do negro brasileiro: processo de um racismo mascarado. Rio de Janeiro: Editora Paz e Terra.

» Oliveira, A. C. (2014). Indígenas crianças, crianças indígenas: subsídios para a construção da Doutrina da Proteção Plural. Curitiba: Juruá.

"Oliveira, A. C. (2016). Lições do assassinato da criança Kaingang. Em: Le Monde Diplomatique Brasil. Disponível em: https://diplomatique.org.br/licoes-do-assassinato-dacrianca-kaingang/

"Parellada, C. I. (2006). Vida Indígena no Paraná: memória, presença, horizontes. Curitiba: PROVOPAR Ação Social/PR. Disponível em: http://estagiocewk.pbworks.com/f/ LIVRO_ PROVOPAR_Kit_Indigena.pdf

»Prefeitura Municipal de Porto Alegre (2011). Decreto no 17.581, de 22 de dezembro de 2011. Porto Alegre: Prefeitura Municipal de Porto Alegre. Disponível em: http://www2.portoalegre.rs.gov.br/cgi-bin/nph-brs?s1=000032691.DOCN.\&l=20\&u=/netaht $\mathrm{ml} / \mathrm{sirel} /$

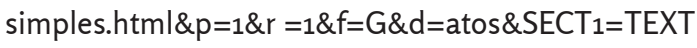

"Szulc, A. (2018). Entre la tutela y la represión: nociones sobre la infancia y la identidad mapuche ante la participación política infantil en Neuquén, Argentina. Em: C. Fonseca; 
C. Medaets; F. B. Ribeiro. Pesquisas sobre família e infância no mundo contemporâneo (pp. 109-129). Porto Alegre: Sulina.

"Szulc, A.; Enriz, N. (2016). La política, las calles y la niñez indígena en Argentina. Em: Cadernos de Campo, 25, 200-221. doi: 10.11606/issn.2316-9133.v25i25p20o-221

" Tassinari, A. (2007). Concepções indígenas de infância no Brasil. Revista Tellus, 7 (13), 1125. Disponível em: www.neppi.org/projetos/gera_anexo. php?id=1282

"Tommasino, K. (1998). Os Novos Acampamentos Wâre Kaingang na cidade de Londrina: mudança e persistência numa sociedade Jê. Rev. Mediações. Londrina, 3 (2), p.66-71, jul/ dez. 